\title{
Uma análise jurídica do caráter subversivo do ser humano a partir do conto A Igreja do Diabo ${ }^{1}$ de Machado de Assis
}

\author{
Marcelo Lucas Ribeiro de Oliveira ${ }^{2}$
}

Machado de Assis nesse clássico expõe com maestria a ambivalência da natureza humana, mostrando que a subversão é um tentação constante para o ser humano, em termos teológicos isso seria associado à queda do homem, a ruptura plena com seu criador, em termos filosóficos tal tendência deverá ser associada à insuficiência do ser humano, sendo que essa também terá lastro na interpretação teológica, tradição que vem dos jansenistas, que traz uma suspeita de que o ser humano não é pleno, não possui todos os recursos para sobreviver, tanto no aspecto biológico como psicológico.

Entretanto para além da discussão moral e teológica, a brilhante obra desse gigante da literatura brasileira, apresenta uma lição jurídica extraordinária, leva o leitor a refletir sobre a cultura e a norma jurídica. Seria possível alterar costumes, hábitos e cosmovisões apenas pela edição de normas, o Direito teria a força para alterar uma cultura?

Claro que no meio jurídico essa discussão já foi superada, se percebeu que o direito é temporal e territorial; existindo uma relação cíclica entre Direito e sociedade, em que a sociedade influencia na elaboração ou mesmo determina a elaboração do direito, enquanto o direito garante a

Artigo recebido em 26 de Janeiro de 2018 e aprovado em 26 de Novembro de 2018

${ }^{1}$ ASSIS, Machado de. A Igreja do Diabo. 1884. Disponível em:

http://www.dominiopublico.gov.br/download/texto/bv000195.pdf>. Acesso em: 16 jan. 2018.

${ }^{2}$ Graduado em Direito pela Faculdade Novos Horizontes, pós graduado em Direito Processual pela Pontifícia Universidade Católica de Minas e advogado. Brasil. E-mail: marcelolucasro@gmail.com 
ordem social. Entretanto o que se observa hodiernamente é uma movimentação contrária a isso, em todo o mundo, em especial no Brasil, pessoas se levantam e usam do aparato estatal para impor através do instrumento legislativo os seus hábitos, a sua própria maneira de ver o mundo. Será que isso pode funcionar?

No conto o Diabo se cansa de sua "doutrina" ser espalhada, não ser sistematizada, se sente menosprezado pelo fato de que Deus tem uma igreja, seus ensinos são institucionalizados e resolve fundar sua própria igreja, decide que já é hora dele ser reconhecido e ter representantes institucionais. No entanto o Diabo não aceita que seu ensino seja um entre outros, não aceita que sua igreja coexista com a igreja tradicional; o Diabo deseja exclusividade. Ele então vai até Deus e lhe expõe seus planos, em tom de afronta e desafio diz a Deus que a sua igreja irá sobrepor a igreja tradicional.

É tempo de obter a vitória final e completa. E então vir dizer-vos isto, com lealdade, para que não me acuseis de dissimulação... (ASSIS, 1884, p.2)

É interessante a análise feita pelo autor, a resposta que Machado de Assis (1884) coloca na boca de Deus é no mínimo impressionante: "Vieste dizê-la, não legitimá-la, advertiu o Senhor". Em seguida o Diabo consente: “Tendes razão, acudiu o Diabo, mas o amor-próprio gosta de ouvir os aplausos dos mestres" (ASSIS, 1884). Embora o Diabo ainda murmure que seria o aplauso de um mestre vencido ele o deseja. Assim acontece hoje com as tentativas de imposição de ideologias sejam politicas, morais ou religiosas, aqueles que tentam impô-las o faz em nome da democracia, do bem comum, da paz social e outras bandeiras do bem.

O Diabo acredita piamente que irá vencer, afinal o ser humano é contraditório, oscila entre o bem e o mal, "entre o livro santo e o bigode do pecado", entretanto ele não percebe que sempre foi assim, e mudar as regras não irá aniquilar essa ambivalência, essa contradição.

Muitos corpos que ajoelham aos vossos pés, nos templos do mundo, trazem as anquinhas da sala e da rua, os rostos tingem-se do mesmo pó, os lenços cheiram aos mesmos cheiros, as pupilas centelham de curiosidade e devoção entre o livro santo e o bigode do pecado. (ASSIS, 1884, p.3) 
Tu és vulgar, que é o pior que pode acontecer a um espírito da tua espécie, replicou-lhe o Senhor. Tudo o que dizes ou digas está dito e redito pelos moralistas do mundo. É assunto gasto; e se não tens força, nem originalidade para renovar um assunto gasto, melhor é que te cales e te retires. Olha; todas as minhas legiões mostram no rosto os sinais vivos do tédio que lhes dás. (ASSIS, 1884, p.3)

O grande problema de quem acredita que basta mudar as regras para implementar um nova cultura, uma nova cosmovisão é que ele ignora a natureza do ser humano, que não é exclusivamente uma coisa só, não é pronto e acabado, está sempre em transformação, em construção; sendo que essa construção se dá por fatores internos e externos, ou seja, a cosmovisão do indivíduo se constrói dentro da sociedade em uma constante dialética entre sua subjetividade e a realidade que está diante dos seus olhos, processo esse que forma a cultura de uma sociedade. Esses profetas da pureza também ignoram toda a história da humanidade que sempre teve uma cosmovisão que reinou, nunca foi suficiente apenas uma norma ou um governante, toda tradição se constrói ao longo de anos, de gerações e não se destrói apenas com a edição de uma norma ou lei. Sobre cosmovisão e a relação do indivíduo com a sociedade em que vive o professor doutor Rodrigo Silva nos esclarece:

Por isso o máximo que podemos dizer é que as cosmovisões que construímos parecem partir ou nascer de três fontes: 1) Noção de pertença [...]. 2) Necessidade de afeto [...]. 3) Identidade [...]. (SILVA, 2018, $1.1177)$

Viu como a cosmovisão é algo ao mesmo tempo individual e coletivo? A diferença é que a individual dura uma vida e a coletiva pode durar por gerações inteiras. (SILVA, 2018, 1.1196)

Tais indivíduos que pensam poder mudar essa concepção apenas com a imposição normativa são como o Diabo se auto define: "Senhor, eu sou, como sabes, o espírito que nega" (ASSIS, 1884, p.3). Esse espírito revolucionário que tudo nega, imagina que pode criar ordem apartir do caos, são pretensos super-homens, conceito do filósofo Friedrich Nietzsche, negando toda referência, toda a história, um ser humano desconectado de qualquer tradição ou valor que o preceda. Segundo o filósofo alemão é necessário superar o homem, transcender a limitação das 
tradições e criar para si mesmo os valores que nortearão a existência, valores que não teriam nenhum elemento transcendente ou metafísico, valores cunhados pela razão, dentro da própria existência do indivíduo.

O super-homem é o sentido da terra. Que a vossa vontade diga: o superhomem seja o sentido da terra!

Eu vos imploro, irmãos, permanecei fiéis à terra e não acrediteis nos que vos falam de esperanças supraterrenas! São envenenadores, saibam eles ou não. (NIETZSCHE, 2011, p.11)

O Diabo oferece uma vida perfeita, tudo que outrora era errado, era proibido passa a ser louvado, a lei agora pune o que antes era permitido, e louva, exalta o que era proibido. Negando qualquer sentido que não venha da vontade, dos apetites, do desejo, em fim; negando qualquer norma, limite ou orientação que não venha da terra, da matéria, assim como propôs Nietzsche.

A princípio todos se empolgam e correm atrás do Diabo, ficam eufóricos, mas com o passar do tempo percebem que é preciso um contra peso, começam a fazer as coisas boas, que antes eram louvadas, mas na nova "gestão", são erradas, às escondidas.

Um dia, porém, longos anos depois notou o Diabo que muitos dos seus fieis, às escondidas, praticavam antigas virtudes. (ASSIS, 1884, p.6)

O Diabo furioso vai reclamar com Deus - sempre assim, o espírito revolucionário nega tudo, inclusive sua própria responsabilidade - e Deus o responde da seguinte maneira:

Que queres tu, meu pobre Diabo? As capas de algodão têm agora franjas de seda, como as de veludo tiveram franjas de algodão. Que queres tu? É a eterna contradição humana. (ASSIS, 1884, p.6) 
Assim como a igreja do Diabo desmoronou sobre si mesma, pois queria impor um projeto de mundo, de realidade que não condizia com a realidade insuficiente, caída, ambivalente e contraditória do ser humano; a ideologia que busca uma coesão plena da sociedade através do imperativo legal terá o mesmo triste fim e irá ruir sobre si mesma. O ser humano sempre buscou ordem, fundamentação, não é em vão que Hans Kelsen cunhou o conceito de norma fundamental para dar a completude lógica ao ordenamento jurídico, explicando que essa norma não é legislada, trata-se de um pressuposto para dar legitimidade, em outras palavras é a norma fundamental, esse pressuposto lógico que dá às leis sua validade, leva os destinatários da norma a agir em consonância a norma.

O fato de alguém ordenar seja o que for não é fundamento para considerar o respectivo comando como válido, quer dizer, para ver a respectiva norma como vinculante em relação aos seus destinatários. Apenas uma autoridade competente pode estabelecer normas válidas; e uma tal competência somente se pode apoiar sobre uma norma que confira poder para fixar normas. A esta norma se encontram sujeitos tanto a autoridade dotada de poder legislativo como os indivíduos que devem obediência às normas por ela fixadas. (KELSEN, 2009, p.216-217)

Essa norma fundamental pode ser traduzida como a cosmovisão - ou um aspecto da cosmovisão - que em uma cultura constitucional se dá pela confiança na supremacia da Carta Constitucional; ou seja, que toda e qualquer norma deve obedecer a Constituição. No que diz respeito ao contexto brasileiro, vale lembrar do princípio democrático, que pressupõe liberdade de pensamento, de crença, de expressão. Nesse sentido a imposição de ideologias ferem esse pressuposto lógico, fazendo com que as normas que visam impor condutas firam essa norma fundamenta, fazendo com que careçam de legitimidade.

Em fim, pode-se perceber que a Igreja do Diabo, sob uma análise jurídica ruiu por carecer de legitimidade, pois não havia uma norma fundamental, um embasamento último que sustentasse a autoridade do Diabo em dizer que as antigas virtudes não deviam ser praticadas, bem como se devesse agir dessa ou daquela forma, do mesmo modo carecem de fundamento os defensores e promotores do "Direito do Diabo", pois esses em nome de uma pretensa evolução e melhoria da sociedade ferem a liberdade de expressão e minimizam ideias e posturas divergentes de sua visão de mundo - ou cosmovisão. 
Não se defende aqui a legitimidade da supremacia de uma classe dominante sobre indivíduos em situação desfavorável, os direitos fundamentais sempre devem ser respeitados, entretanto é imperioso reconhecer que a tentativa de imposição ideológica através do "Direito" sendo esse direito que aqui denomina-se "Direito do Diabo" fere nuclearmente esses mesmos direitos fundamentais que tais revolucionários dizem estar defendendo; pois quando se cala ou se ridiculariza pensamentos dissonantes não se está promovendo a liberdade de expressão, de crença e de pensamento; em outras palavras não se deve haver censura, mesmo que essa seja em nome de um discurso aparentemente democrático. Como a frase atribuída a Voltaire (embora não esteja presente em suas obras, essa frase se afina perfeitamente ao pensamento do célebre filósofo): "Posso não concordar com o que você diz; mas defenderei até a morte seu direito de dizê-lo". Claro que excessos devem ser punidos, mas jamais se pode usar desse risco de dano para se censurar.

O que se defende aqui não é inercia ou estagnação, mas simplesmente a tese já há muito estabelecida de que a Lei acompanha a sociedade não a constitui, a sociedade é anterior à Lei, premissa essa que parece ter sido esquecida pelos defensores do "Direito do Diabo" que tentam forjar uma sociedade nos moldes de seus ideais através da edição de leis, em nome de suas pretensas boas intenções que nem sempre se verificam na prática.

Ambivalências e contradições são partes constituintes do ser humano, diante disso a sociedade, as instituições terão que lidar com toda essa tensão, não adianta pensar que eliminando o erro (ou pecado como no conto machadiano) fará uma sociedade perfeita, não é negando o erro e aplaudindo as debilidades que se vai elevar a sociedade. Não há caminho fácil, democracia e pluralidade é conviver com diferenças, alteridades e ambivalências, qualquer tentativa de exclusão é uma tentativa antidemocrática, antijurídica, uma tentativa "diabólica" de estabelecer a "igreja do diabo" através do "direito do diabo".

Portanto o que se percebe é que nem se trata da possibilidade de se alterar a cultura ou não, as mudanças ocorrem naturalmente e pontualmente pela própria dinâmica das relações humanas, de maneira independente do Direito; trata-se, em uma análise jurídica, de uma clara ilegitimidade da imposição ideológica, ferindo os próprios direitos fundamentais que são inalienáveis.

Por fim além da ambivalência presente na natureza humana, o celebre imortal expõe uma verdadeira condição humana expressa em um velho ditado brasileiro: "de boas intenções o inferno está cheio”. 


\section{Referências}

ASSIS, Machado de. A Igreja do Diabo. 1884. Disponível em: <http://www.dominiopublico.gov.br/download/texto/bv000195.pdf>. Acesso em: 16 jan. 2018.

KELSEN, Hans. Teoria pura do Direito. 8. ed. São Paulo: Wmf Martins Fontes, 2009. Tradução de João Baptista Machado.

NIETZSCHE, Friedrich. Assim Falou Zaratustra. São Paulo: Companhia das Letras, 2011. 403 p. Tradução de Paulo César Lima de Souza.

SILVA, Rodrigo. O Ceticismo da fé: uma dúvida, uma certeza, uma distorção. Barueri, SP: Ágape, 2018. Versão Kindle. 